\title{
Bayesian inference on field data for genetic parameters for some reproductive and related traits of Nellore cattle (Bos indicus)
}

\author{
Carina Ubirajara de Faria ${ }^{1}$, Cláudio de Ulhôa Magnabosco ${ }^{2}$, Arcadio de los Reyes ${ }^{3}$, Raysildo Barbosa Lôbo ${ }^{4}$, \\ Luiz Antônio Framartino Bezerra ${ }^{4}$ and Roberto Daniel Sainz ${ }^{5}$ \\ ${ }^{1}$ UNIDERP, Campo Grande, MS, Brazil \\ ${ }^{2}$ Embrapa Cerrados/Arroz e Feijão, Planaltina, DF, Brazil. \\ ${ }^{3}$ Escola de Veterinária, Departamento de Produção Animal, Universidade Federal de Goiás, Goiânia, \\ GO, Brazil. \\ ${ }^{4}$ Departamento de Genética, Faculdade de Medicina de Ribeirão Preto, Universidade de São Paulo, \\ Ribeirão Preto, SP, Brazil. \\ ${ }^{5}$ Animal Science Department, University of California, Davis, USA.
}

\begin{abstract}
We used Gibbs sampling in single and two-trait animal models to estimate genetic parameters for some reproductive and related traits of Nellore cattle (Bos indicus). Female traits were age at first calving (AFC), cumulative productivity (CP) and adult weight (AW). For males, scrotal circumferences at 365 and 450 days of age were analyzed. Gibbs sampling using the 'Multiple Trait using Gibbs Sampling under Animal Model' (MTGSAM) program of Van Tassel and Van Vleck was used to estimate the (co)variance components of the traits and conduct genetic analyses. Heritabilities were $\mathrm{AFC}=0.26, \mathrm{AW}=0.36$ and $\mathrm{CP}=0.25$ under the single-trait animal model. The mean, mode and median estimates for genetic parameters obtained from the marginal posterior distributions were similar for all traits except AW, which presented lower values for the mode than the mean and median. However, the marginal posterior distributions for the traits studied presented a tendency toward normality. Favorable, but low, negative genetic correlations were found between male scrotal circumference and female age at first calving. The reproductive traits showed medium-magnitude heritabilities, which indicates that these traits should respond to selection and therefore should be included in genetic improvement programs.
\end{abstract}

Key words: bayesian inference, genetic parameters, heritabilities, Nellore cattle, reproductive traits.

Received: October 26, 2005; Accepted: September 13, 2006.

\section{Introduction}

The Brazilian cattle population consists of 192 million head, of which approximately $80 \%$ are Bos indicus (Zebu) in their genetic composition. However, despite its large size, the Brazilian beef industry is notable for its low productivity and elucidating the factors influencing the performance of Zebu cattle, especially the genetic and environmental components of reproduction, is indispensable for improving domestic beef cattle productivity. The Nellore breed makes up more than $70 \%$ of the Zebu cattle in Brazil and thus plays a fundamental role in the total population productivity of the Brazilian heard, because of which Nellore cattle must be given the most attention where reproductive efficiency of Brazilian beef cattle is concerned.

Send correspondence to Carina Ubirajara de Faria. Avenida Marcos de Freitas Costa 897, Daniel Fonseca, 38400328 Uberlândia, MG, Brazil. E-mail: carina@cnpaf.embrapa.br or carina@ancp. org.br.
As pointed out by Pereira et al. (2002), reproduction is an essential component for the profitable economic performance of any production system. However, the methodology for analysis of reproductive traits measured directly in the female has been little explored in practical terms due to both the low heritability of these traits and lack of information or inadequate data. This reflects the greater emphasis given by genetic improvement programs to growth traits, since reproductive traits have been considered of low heritability and not very responsive to selection. However, it is now known that heritability of reproductive efficiency is much higher than has been commonly quantified, especially in tropical countries (Pereira et al., 1991). However, for genetic selection to be effective it is essential to understand the biological behavior of reproductive traits, especially the real genetic and environmental contributions to the phenotype of these traits and the magnitude of the response to selection. 
Bayesian methods have recently emerged as an option for solving problems related to the evaluation of genetic merit in animal populations. Markov Chain Monte Carlo (MCMC) methods, including Gibbs Sampling may be used as a tool for Bayesian inference. Gibbs sampling is a stochastic integration procedure used to estimate joint and marginal distributions of all parameters in a model from their full conditional posterior distributions. This method has been suggested for use in animal breeding, particularly when data does not fit a normal distribution (Jensen et al., 1994; Sorensen et al., 1994; Wang et al., 1994; Van Tassel and Van Vleck, 1996; Magnabosco et al., 2000; Chang et al., 2001). During the study described in this paper we applied the Gibbs sampling and two-trait animal models to estimate the covariance components and genetic parameters for some Nelore cattle reproductive and related traits as well as the genetic correlations between scrotal circumference at 365 and 450 days of age and the age of related females at first calving.

\section{Materials and Methods}

We obtained information in the form of records on 69,025 Nellore cattle from the Nellore Breed Genetic Improvement Program (Programa de Melhoramento Genético da Raça Nelore PMGRN), see www.ancp.org.br, administered by Associação Nacional de Criadores e Pesquisadores (ANCP), Ribeirão Preto-SP, Brazil. The records in included information on the relationship between animals. All the cattle had been raised on pasture across diverse Brazilian regions, where the predominant climate ranges from subtropical hot humid to tropical hot humid, with two distinct seasons, one dry and the other rainy.

The female traits analyzed were age at first calving (16,347 records), adult weight (5,934 records) and cumulative productivity $(7,681$ records) while the male traits were scrotal circumference at 365 days (6,911 records) and 450 days (8,266 records), all of which are defined below. The contemporary groups for age at first calving and cumulative productivity consisted of herd, year and season, while for adult weight the contemporary group was formed by animals born on the same farm during the same year and season and weighed in the same year and season, considering a rainy season (October to March, spring and summer in the Southern Hemisphere) and a dry season (April to September, autumn and winter). For each animal, we defined adult weight as the first weight measured in the age of four the twelve years. Age-of-dam effects were grouped into six classes, i.e. 3, 4, 5, 6, 7 to 10 and 11 years of age at calving. Preliminary analyses using the GLM (Generalized Linear Model) procedure of the Statistical Analysis Software version 8.1 (Anon, 1996) showed that the age-of-dam effect was not significant in relation to age at first calving, because of which the age-of-dam effect was not considered as a fixed effect for age at first calving. For scrotal circumfer- ence traits, the contemporary groups consisted of animals born on the same farm during the same year and season.

Cumulative productivity (CP) was calculated using the expression cited by Schwengber et al. (2001):

$$
C P=\frac{\bar{W} \times n_{p} \times c_{a}}{D A C_{n}-C_{i}}
$$

where $\bar{W}$ is the mean calf weight at weaning, $n_{p}$ is the total number of weaned calves produced, $C_{a}$ is a constant equal to 365 days which makes it possible to express fertility on an annual basis, $D A C_{n}$ is the age of the dam at last calving and $C_{i}$ is a constant equal to 550 days (approximately 18 months). The $C_{a}$ and $C_{i}$ constants are used because a goal of the PMGRN is that first calving occurs when a dam is about 30 months old.

The analyses were conducted by fitting single and two-trait animal models. In matrix notation the general mixed linear model was:

$$
y=X \beta+Z u+e
$$

where $\beta$ is the fixed effects vector associated with the observation (records) vector $y$ by the known matrix $X$ and $u$ is the random effects vector (additive genetic animal effects only in this study) associated with records in $y$ by the incidence matrix $Z$ and $e$ is the residuals vector. From these definitions, it is considered that:

$$
E[\gamma]=X \beta \text { and } \operatorname{var}[\gamma]=Z \Sigma Z^{\prime}+R
$$

with $\Sigma=\operatorname{var}(u)=A \sigma_{a}^{2}$ and $R=I \sigma_{e}^{2}$ in the single-trait model, where $\sigma_{a}^{2}$ is the additive genetic variance and $\sigma_{e}^{2}$ the residual variance, $A$ is the numerator relationship matrix among animals and $I$ is the appropriate identity matrix. In the two-trait model, $\Sigma=G \otimes A$ and $R=I \otimes R^{+}$where $G$ is additive genetic effects matrix for the two-traits and $R^{+}$is residuals matrix for the traits measured for each animal.

Bayesian inference was applied using the 'Multiple Trait using Gibbs Sampling under Animal Model' (MTGSAM) program developed by Van Tassel and Van Vleck (1996). Bayesian analyses make it possible to estimate the posterior marginal densities of the genetic parameters, and from these densities to calculate the errors in the estimates of the parameters, making them more informative (Gianola et al., 1994). Gibbs Sampling produced 1,800 samples of (co)variance components and genetic parameters and was implemented using a long chain scheme (Jensen et al., 1994; Sewalem and Johansson, 2000), a 200,000 cycle sampler chain, a 20,000 cycle burn-in and a 100 cycle thinning interval in which one sample was collected from every 100 samples to avoid possible correlation between consecutive samples. The Gibbsit program (Raftery and Lewis, 1994) was used to evaluate burn-in for all (co)variance components and also to calculate the thinning interval to determine the frequency of retaining sampled values so that those samples were uncorrelated for each parameter. 
The initial values used reflected no previous knowledge of the parameters.

\section{Results and Discussion}

The number of records analyzed, mean values, coefficients of variation, and minimum and maximum values for each of the reproductive traits measured are shown in Table 1. These values are in general agreement with those reported in the literature for Nellore cattle. We found that the observed mean age at first calving was 36.22 months, indicating the need to work intensively with sexual precocity to identify superior genotypes for this trait and attain more rapid genetic progress. Considering that reproductive and nutritional management significantly influence the age at first calving, Bergmann et al. (1998) and Lôbo (1998) reported that correct management measures can reduce that age to as little as 24 months. One of the procedures recommended by the PMGRN is that females should be exposed to males starting at 12 to 14 months of age, to allow identification of the most precocious females. In our study, cumulative productivity showed an average of $134 \mathrm{~kg}_{\text {year }}{ }^{-1}$ of age beyond 18 months, consistent with the values reported in the literature (Rosa et al., 2001; Schwengber et al., 2001). However, it is important to point out that this mean is below the mean weaning weight $(191 \mathrm{~kg})$ for cattle participating in the PMGRN, possibly due to the fact that cumulative productivity contains the calving interval, often greater than 365 days, in its denominator. This is reflected in a reduction of the mean weights of weaned calves per year.

Our heritability estimates were 0.26 for age at first calving, 0.36 for adult weight and 0.25 for cumulative productivity (Table 2). Recent studies have also reported middle to high magnitude heritabilities for these traits in Nellore cattle (Koots et al., 1994; Mercadante et al., 2000; Pereira et al., 2000; Pereira et al., 2002; Dias et al., 2004). Published estimates of age at first calving heritability for Nellore cattle vary from 0.02 (Gressler et al., 2000) to 0.46 (Pereira et al., 1991) and taken together with our results suggest that age at first calving presents medium heritability and is thus recommended as a selection criterion for sexual precocity. However, nutritional and reproductive management must also be adequate to obtain satisfactory responses. Our adult weight heritability estimate of 0.36 was similar to the values obtained by Pereira $e t$ al. (1991), and confirms the well known genetic component for adult weight which needs to be included in genetic improvement programs. This high heritability presents an op-

Table 1 - Descriptive statistics for all variables included in the analyses.

\begin{tabular}{lccccc}
\hline Trait & $\begin{array}{c}\text { Number of cattle } \\
\text { (n) }\end{array}$ & Mean trait value & $\begin{array}{c}\text { Coefficient of } \\
\text { variation (\%) }\end{array}$ & $\begin{array}{c}\text { Minimum trait } \\
\text { value }\end{array}$ & $\begin{array}{c}\text { Maximum trait } \\
\text { value }\end{array}$ \\
\hline Age at first calving (months) & 16,347 & 36.22 & 9.44 & 23.00 & 44.00 \\
Adult weight (kg) & 5,934 & 450.00 & 13.13 & 300.00 & 600.00 \\
Cumulative calf productivity (kg year $\left.{ }^{-1}\right)$ & 7,681 & 134.00 & 21.18 & 80.02 & 224.43 \\
Scrotal circumference at 365 days $(\mathrm{cm})$ & 6,911 & 19.37 & 10.72 & 11.10 & 29.00 \\
Scrotal circumference at 450 days $(\mathrm{cm})$ & 8,266 & 22.53 & 12.01 & 11.40 & 32.50 \\
\hline
\end{tabular}

Table 2 - Descriptive statistics of variance components and heritabilities for age at first calving, adult weight and cumulative productivity obtained from single-trait analyses by Gibbs Sampling.

\begin{tabular}{|c|c|c|c|c|c|c|}
\hline Trait and parameter & Mean & Mode & Median & Sample variance $\left(\sigma_{k}^{2}\right)$ & Standard deviation & Confidence interval $(95 \%)$ \\
\hline \multicolumn{7}{|l|}{ Age at first calving } \\
\hline Additive genetic variance $\left(\sigma_{a}^{2}\right)$ & 1.85 & 1.90 & 1.85 & 0.0264 & 0.16 & 1.53 to 2.17 \\
\hline Residual variance $\left(\sigma_{e}^{2}\right)$ & 5.29 & 5.25 & 5.29 & 0.0188 & 0.14 & 5.01 to 5.57 \\
\hline Heritability $\left(h^{2}\right)$ & 0.26 & 0.26 & 0.26 & 0.0004 & 0.02 & 0.22 to 0.30 \\
\hline \multicolumn{7}{|l|}{ Adult weight } \\
\hline Additive genetic variance $\left(\sigma_{a}^{2}\right)$ & 795.2 & 768.9 & 793.2 & 6430.5 & 80.2 & 634.9 to 955.6 \\
\hline Residual variance $\left(\sigma_{e}^{2}\right)$ & 1420.5 & 1418.5 & 1420.6 & 4597.7 & 67.8 & 1284.9 to 1556.1 \\
\hline Heritability $\left(h^{2}\right)$ & 0.36 & 0.36 & 0.36 & 0.0010 & 0.03 & 0.30 to 0.42 \\
\hline \multicolumn{7}{|l|}{ Cumulative productivity } \\
\hline Additive genetic variance $\left(\sigma_{a}^{2}\right)$ & 105.4 & 105.5 & 105.2 & 175.8 & 13.3 & 78.9 to 131.9 \\
\hline Residual variance $\left(\sigma_{e}^{2}\right)$ & 318.0 & 318.0 & 318.0 & 123.2 & 11.1 & 295.8 to 340.2 \\
\hline Heritability $\left(h^{2}\right)$ & 0.25 & 0.25 & 0.25 & 0.0008 & 0.03 & 0.19 to 0.31 \\
\hline
\end{tabular}


portunity to reduce (or increase) the adult size of females by applying selective pressure on herds as necessary. Our estimated cumulative productivity heritability value of 0.25 shows that although this trait is expressed in kilograms of weaned calves per year it is a reproductive trait with lower heritability than production traits such as weaning weight (Schwengber et al., 2001). This is explained by the fact that cumulative productivity is a compound index that includes the calving interval, which is under great environmental influence.

The posterior variances, standard deviations and credibility intervals along with the means, modes and medians of the variance components and heritabilities for the single-trait models of the female traits are shown in Table 2. The means, modes, and medians for the reproductive trait variance components appear similar to each other. For the heritability values, the various measures of central tendency had were identical, indicating that these posterior marginal distributions tended to symmetry (Figure 1).
Two-trait analyses with age at first calving and scrotal circumference at either 365 or 450 days of age were also carried out. The (co)variance component and genetic parameter estimates obtained are presented in Table 3. The age at first calving heritability coefficient was greater in two-trait than in single-trait analyses. With the use of twotrait analyses, estimates of additive genetic covariances, residual covariances (when it exists) and correlation between traits can be obtained, which is not possible with single-trait analyses. For the two-trait analyses, the posterior means, modes and medians of the (co)variance components were similar and the genetic parameters were practically identi$\mathrm{cal}$, as can be seen from the posterior marginal distributions presented in Figure 2.

The genetic correlations between scrotal circumference at 365 and 450 days of age and age at first calving were both identical (-0.19). These results are consistent with those previously reported for Nellore cattle (Gressler et al., 2000; Mercadante et al., 2000; Pereira et al., 2000). This in-
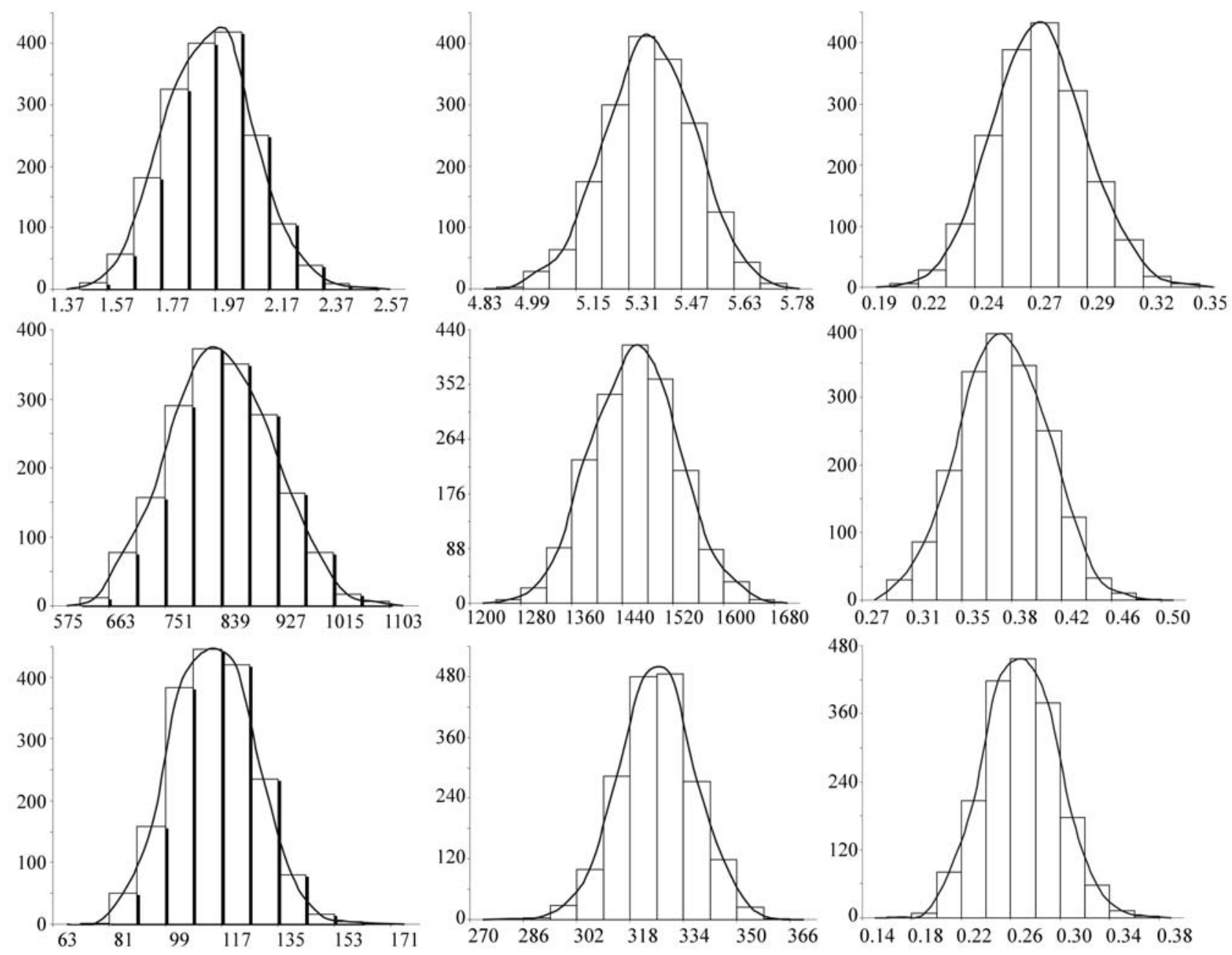

Figure 1 - Posterior density distributions of additive genetic variance $\left(\sigma_{\mathrm{a}}^{2}\right)$, residual variance $\left(\sigma_{\mathrm{e}}^{2}\right)$ and heritability $\left(\mathrm{h}_{\mathrm{d}}^{2}\right)$ for age at first calving (upper), adult weight (central) and cumulative productivity (lower) by single-trait analyses. 
dicates that age at first calving may be used as a selection criterion for sexual precocity and that the selection of bulls for scrotal circumference can result in daughters with a decreased age at first calving.
Our data allowed several conclusions to be drawn. Reproductive traits presented heritabilities of medium magnitude and medium-high genetic variance, which indicates that they may be improved by genetic selection and

Table 3 - Descriptive statistics for variance components and genetic parameters for age at first calving (AFC) and scrotal circumference at 365 (SC365) and 450 (SC450) days based on two-trait analyses using Gibbs Sampling.

\begin{tabular}{|c|c|c|c|c|c|c|c|c|}
\hline \multirow[b]{2}{*}{ Traits } & \multicolumn{5}{|c|}{ Variance components $^{\dagger}$} & \multicolumn{3}{|c|}{ Genetic parameters ${ }^{\ddagger}$} \\
\hline & $\sigma_{a_{1}}^{2}$ & $\sigma_{a_{12}}$ & $\sigma_{a_{2}}^{2}$ & $\sigma_{e_{1}}^{2}$ & $\sigma_{e_{2}}^{2}$ & $h_{1}^{2}$ & $h_{2}^{2}$ & $r_{g_{12}}$ \\
\hline \multicolumn{9}{|l|}{$\mathrm{SC} 365_{1}$ and $\mathrm{AFC}_{2}$} \\
\hline Mean & 2.06 & -0.50 & 3.43 & 1.02 & 4.96 & 0.67 & 0.41 & -0.19 \\
\hline Mode & 2.09 & -0.52 & 3.42 & 1.06 & 5.00 & 0.67 & 0.41 & -0.19 \\
\hline Median & 2.05 & -0.51 & 3.43 & 1.02 & 4.97 & 0.67 & 0.41 & -0.19 \\
\hline Sample variance $\left(\sigma_{k}^{2}\right)$ & 0.034 & 0.028 & 0.106 & 0.016 & 0.057 & 0.0022 & 0.0011 & 0.0038 \\
\hline Standard deviation & 0.18 & 0.17 & 0.32 & 0.13 & 0.24 & 0.05 & 0.03 & 0.06 \\
\hline \multicolumn{9}{|l|}{$\mathrm{SC} 40_{1}$ and $\mathrm{AFC}_{2}$} \\
\hline Mean & 3.42 & -0.65 & 3.36 & 2.13 & 5.03 & 0.61 & 0.40 & -0.19 \\
\hline Mode & 3.40 & -0.71 & 3.31 & 2.12 & 5.00 & 0.62 & 0.40 & -0.20 \\
\hline Median & 3.42 & -0.66 & 3.35 & 2.13 & 5.03 & 0.61 & 0.40 & -0.19 \\
\hline Sample variance $\left(\sigma_{k}^{2}\right)$ & 0.074 & 0.045 & 0.098 & 0.036 & 0.052 & 0.0015 & 0.0010 & 0.0039 \\
\hline Standard deviation & 0.27 & 0.21 & 0.31 & 0.19 & 0.23 & 0.04 & 0.03 & 0.06 \\
\hline
\end{tabular}

${ }^{\dagger} \sigma_{a_{1}}^{2}=$ additive genetic variance of trait $1 ; \sigma_{a_{12}}=$ additive genetic covariance between traits 1 and $2 ; \sigma_{a_{2}}^{2}=$ additive genetic variance of trait $2 ; \sigma_{e_{1}}^{2}=$ residual variance of trait 1 ; and $\sigma_{e_{2}}^{2}=$ residual variance of trait 2 .

${ }^{\ddagger} h_{1}^{2}=$ heritability of trait $1 ; h_{2}^{2}=$ heritability of trait 2 ; and $r_{g_{12}}=$ genetic correlation between traits 1 and 2 .
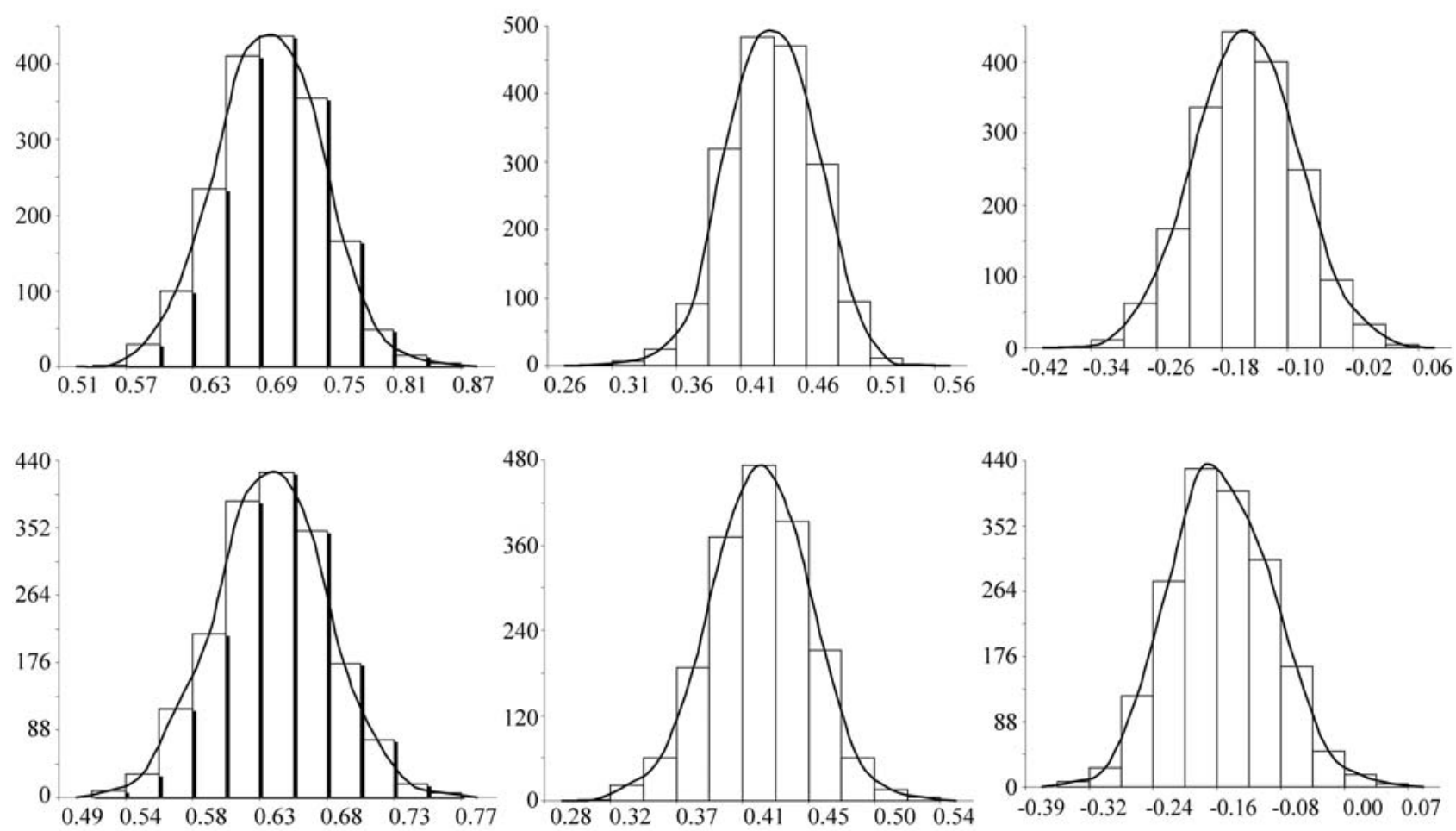

Figure 2 - Posterior densities estimates of genetic parameters for scrotal circumference at 365 days of age (1) and (2) age at first calving (upper) and scrotal circumference at 450 days of age (1) and (2) age at first calving (lower) from two-trait analyses using Gibbs sampling. 
should be included in genetic improvement programs. Multi-trait analyses should be utilized in the estimation of (co)variance components and genetic parameters because they enable the estimation of correlations between traits thus increasing the accuracy of genetic prediction. In this study, two-trait analyses presented advantages in comparison with single-trait analyses, possibly due to the scrotal circumference measurements improving the accuracy of prediction of the genetic merit of the age at first calving trait. The low genetic correlations obtained in this study indicate that there is little possibility in improving female reproductive traits by selection for male scrotal circumference. However, these results should not be generalized because the size and structure of the database analyzed may have been insufficient to obtain absolutely trustworthy estimates of the parameters.

\section{Acknowledgments}

We are grateful to the breeders participating in the Genetic Improvement Program of the Nellore Breed for providing the data, and especially to the Brazilian Society of Breeders and Researchers (ANCP) for editing the data base. Thanks are also due to Guilherme J. Rosa for valuable help in editing this manuscript. We are also indebted to the CNPq and Embrapa Cerrados for financial support.

\section{References}

Anon (1996) SAS User's Guide for Windows Environment. 6.12 edition. SAS Institute Inc, Cary, $842 \mathrm{pp}$.

Bergmann JAG, Gressler SL and Pereira CS (1998) Avaliação de fatores genéticos e de ambiente sobre diferentes características reprodutivas de fêmeas da raça Nelore em regime de estação de monta restrita. Arq Bras Med Vet Zootec 50:633-645.

Chang YM, Rekaya R, Gianola D and Thomas DL (2001) Genetic variation of lactation curves in dairy sheep: A Bayesian analysis of wood's function. Livest Prod Sci 71:241-251.

Dias LT, Elfaro L and Albuquerque LG (2004) Estimativas de herdabilidade para idade ao primeiro parto de novilhas da raça Nelore. Rev Bras Zootec 33:97-102.

Gianola D, Rodriguez-Zaz S and Shook GE (1994) The Gibbs sampler in the animal model: A primer. Foulley JL and Molenat M (eds) Séminaire Modele Animal. I'institut National de la Recherche Agronomique, Departament de Genetique Animale, Paris, pp 47-56.

Gressler SL, Bergmann JAG, Pereira CM, Penna VM, Pereira CS, Pereira JCC and Gressler MGM (2000) Estudo das associações genéticas entre perímetro escrotal e características reprodutivas de fêmeas da raça Nelore. Arq Bras Med Vet Zootec 29:427-437.

Jensen J, Wang CS, Sorensen DA and Gianola D (1994) Bayesian inference on variance and covariance components for traits influenced by maternal and direct genetic effects, using the Gibbs sampler. Acta Agric Scand 44:193.

Koots KR, Gibson JP, Smith C and Wilton JW (1994) Analyses of published genetic parameter estimates for beef production traits. 1. Heritability. J Anim Breed Genet 62:309-338.

Lôbo RNB (1998) Genetic parameters for reproductive traits of Zebu cows in the semi-arid region of Brazil. Livest Prod Sci 55:245-248.

Magnabosco CU, Lôbo RB and Famula TR (2000) Bayesian inference for genetic parameter estimation on growth traits for Nellore cattle in Brazil, using the Gibbs sampler. J Anim Breed Genet 117:169-188.

Mercadante MEZ, Lôbo RB and Oliveira HN (2000) Estimação de (co)variâncias entre características de reprodução e de crescimento em fêmeas de um rebanho Nelore. Rev Bras Zootec 29:997-1004.

Pereira E, Eler JP and Ferraz JBS (2000) Correlação genética entre perímetro escrotal e algumas características reprodutivas da raça Nelore. Rev Bras Zootec 29:1676-1683.

Pereira E, Eler JP and Ferraz JBS (2002) Genetic analysis of reproductive traits in Nellore cattle. Pesq Agropec Bras 37:703-708.

Pereira JCC, Ayala JMN and Oliveira HN (1991) Efeitos genéticos e não-genéticos sobre a idade ao primeiro parto e o intervalo entre partos de duas populações da raça Nelore. Arq Bras Med Vet Zootec 42:93-102.

Raftery AE and Lewis SM (1994) Gibbsit version 2.0. Software, http://lib.stat.cmu.edu/general/gibbsit

Rosa AN, Lôbo RB, Oliveira HN, Bezerra LAF and Reyes LR (2001) Mature weight of Nellore cows from selection herds in Brazil. Rev Bras Zootec 30:1027-1036.

Schwengber EB, Bezerra LAF and Lôbo RB (2001) Accumulated productivity as selection criteria in Nellore breeds females. Cienc Rural 31:483-486.

Sewalem A and Johansson K (2000) Egg weight and reproduction traits in laving hens: Estimation of direct and maternal genetic effects using Bayesian approach via Gibbs sampling. J Anim Sci 70:9-16.

Sorensen DA, Wang CS, Jensen J and Gianola D (1994) Bayesian analysis of genetic change due to selection using Gibbs sampling. Genet Sel Evol 26:333-60.

Van Tassel CP and Van Vleck LD (1996) Multiple-trait Gibbs sampler for animal models: Flexible programs for Bayesian and likelihood-based (co)variance component inference. J Anim Sci 74:2586-2597.

Wang CS, Gianola D, Sorensen DA, Jensen J, Christensen A and Rutledge JJ (1994) Response to selection for litter size in Danish Landrace pigs: A Bayesian analysis. Theor Appl Genet 88:220.

Associate Editor: Pedro Franklin Barbosa 